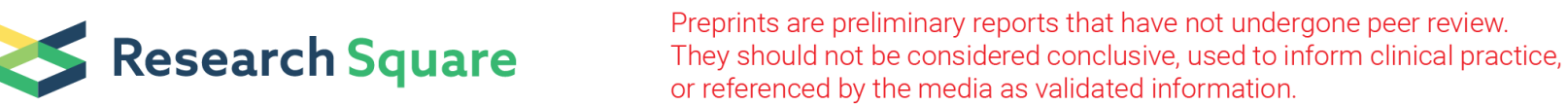

\section{Factors associated with the practice of exclusive breastfeeding for six months among mothers on antiretroviral therapy in the Eastern Cape, South Africa}

PROF DANIEL TER GOON

UNiversity of Fort Hare

Anthony Idowu Ajayi

African Population and Health Research Center

OLADELE VINCENT ADENIYI ( $\nabla$ vincoladele@gmail.com )

Walter Sisulu University https://orcid.org/0000-0003-0216-6701

\section{Research}

Keywords: Infants, Exclusive Breastfeeding, HIV, Antiretroviral therapy, South Africa

Posted Date: July 8th, 2020

DOI: https://doi.org/10.21203/rs.3.rs-40582/v1

License: (c) (i) This work is licensed under a Creative Commons Attribution 4.0 International License. Read Full License

Version of Record: A version of this preprint was published on February 16th, 2021. See the published version at https://doi.org/10.1186/s13006-021-00366-4. 


\section{Abstract \\ Background}

Despite the beneficial health effects of exclusive breastfeeding (EBF) for infants, the practice of EBF remains low in South Africa, a country burdened with HIV. Given that the factors limiting EBF are multifactorial and context-specific, we sought to examine the factors influencing EBF practice among mothers on antiretroviral therapy (ART) in the Eastern Cape, South Africa.

\section{Methods}

This was a prospective cross-sectional study of 469 parturient women enlisted in the prevention of mother-to-child HIV transmission cohort study in the Eastern Cape. A structured questionnaire was used to collect relevant socio-demographic, lifestyle and maternal information. Bivariate and multivariate logistic regression analyses were performed to assess associations between socio-demographic, lifestyle factors and EBF.

\section{Results}

EBF for six months was practised by a few women (32.0\%). The prevalence of EBF was significantly higher among married women (36.8\%), unemployed women (36.6\%), non-smokers (32.7\%), and those who never drank alcohol (37.0\%). Unemployed women (AOR $=1.66,95 \% \mathrm{Cl}: 1.08-2.56)$ and those with grade 12 or less level of education ( $A O R=2.76,95 \% \mathrm{Cl}$ : $1.02-7.49$ ) had a higher likelihood of practising EBF for six months compared to employed women and women who attained tertiary level of education. While mothers who take alcohol ( $A O R=0.54,95 \% \mathrm{Cl}: 0.34-0.85)$ were less likely to practice EBF for six months compared to those who never drank alcohol.

\section{Conclusions}

Factors contributing to the low prevalence of EBF among mothers in this setting are employment, tertiary education and alcohol consumption. Strategies should target these socioeconomic indicators and lifestyle behaviour in the region.

\section{Background}

Exclusive breastfeeding (EBF) could save the lives of infants and prevent mother-to-child transmission (PMTCT) of HIV infection [1, 2], especially in a high burdened setting like South Africa [3, 4]. Between 2010 and 2015, South Africa has made policy changes in infant feeding practices and PMTCT guidelines. The policy changes resulted in the replacement of free infant formula for EBF for six months policy. Mothers are counselled to observe the six-month EBF, continue to breastfeed beyond six months, 
having introduced complementary feeding. Also, the new policy recommended the adoption of Option B+ as a lifelong ART strategy for all HIV-infected pregnant and postpartum women, irrespective of their immune suppression status or infant feeding mode $[1,5,6]$.

Established global evidence has shown that exclusive breastfeeding prevents both the incidence of and mortality from diarrhoea, which is commonly associated with mixed feeding practices and poor infant formula feeding practices [7]. Overall, EBF confers the benefits of essential nutrients and strong immune systems, reduction in the risk of malnutrition and diarrheal associated-illnesses, which are the leading causes of infant mortality in developing nations $[1,8-10]$. Worryingly, even with available data demonstrating unequivocal benefits of EBF, mothers often do not abide by the recommended six months of EBF [11-13]; thus, putting infants at high risk of death. The low EBF prevalence is underpinned by several factors, thus suggesting that there is more to learn and understand regarding the prevailing reasons for the reluctance of mothers to breastfeed their infants exclusively. Previous studies conducted in South Africa have indicated contradictory infant feeding messages from older relatives, such as grandmothers, and health care workers, poor socio-economic indicators and the fear of transmitting HIV to the infant as among the reasons for mixed-feeding practices $[10,14]$.

EBF rates are reportedly low in many countries, despite the manifold benefits accruable from breastfeeding [15-17]. As reported by Victoria et al. (16) study, only $37 \%$ of children are exclusively breastfed in developing countries. In sub-Saharan Africa, the prevalence of EBF is 36\% [17], which is very low compared with the global EBF target rate set at $50 \%$ by 2025 [18]. In South Africa, the government effort has yielded some modest improvement in EBF rates by mothers living with HIV over the years [19], but with an estimation of $31.6 \%$ EBF rate, the country still remains below global targets $[15,20,21]$. The fear of HIV transmission and status disclosure are among the reasons for the low prevalence of EBF [22, 23].

Considering the high HIV epidemic in South Africa, with approximately 7.7 million people with HIV [24), understanding the factors associated with EBF is essential in crafting strategies to support and sustain appropriate breastfeeding practices to increase the prevalence of EBF. Even though previous studies have examined the prevalence of EBF among lactating mothers living with HIV in South Africa $[10,15,17,20$, 25-28], scanty information exists in the Eastern Cape, a province with a twin burden of HIV epidemic and poverty. Given that factors affecting EBF practices vary among countries and even within the sub-groups of populations [29], contextual information on the prevalence and determinants of EBF is vital to inform context-specific interventions. Hence, this study seeks to examine the prevalence and the factors influencing EBF practices among mothers on antiretroviral therapy in the Eastern Cape Province, South Africa.

\section{Methods}

\section{Study Design, Settings, population and sample}


This prospective cross-sectional study was conducted between January to May 2018 and forms part of a larger project to assess maternal and infant outcomes for the prevention of mother-to-child transmission programme in the Eastern Cape, South Africa. Aspects of the methodology have been previously published elsewhere [30,31]. Briefly, the target population were parturient women on ART and their infants attending maternity health facilities at Frere, Cecilia Makiwane and Bisho hospitals. The baseline study was carried out between September 2015 and May 2016 in the Eastern Cape, South Africa. All the parturient women on ART gave consent to be contacted for the follow-up study. A sample size of 469 participants was estimated from a total population of 1709 participants for the follow up study. This sample size was estimated by using the Cochran's formula; at a precision level of $+/-4 \%$, confidence level of $95 \%$ and $10 \%$ possible attrition. Participants were eligible for the follow up study if they had live infants. Participants who had died, relocated from the region or were inaccessible via telephone, were excluded from the study.

The Research Ethics Committee of the Walter Sisulu University approved the research protocol. The nature and scope of the study were explained to the participants, who all gave informed consent before data collection.

\section{Data Collection Procedure}

Participants were contacted telephonically to participate in this study. Each participant was provided with an option to either visit the nearest hospital for a face-to-face interview or they consented to a telephonic interview. Two research assistants were trained to complete the interviewer-guided interview using a predesigned and validated questionnaire. They were trained mainly on the data collection instruments and the sensitivity of the topic under study.

Participants for telephonic interviews were asked to provide a convenient time for the interview. Research assistants could fluently speak and write English and the local language-IsiXhosa. A structured questionnaire was designed to obtain information on socio-demographic variables (age, employment, marital status and level of education), postpartum adherence to ART, and behavioural lifestyles (smoking and alcohol intake).

\section{Outcome variable}

The primary outcome of interest was EBF practice in the first six months. This was measured by asking mothers if they breastfeed their baby exclusively and if yes to state their duration of EBF in months.

\section{Independent variables}

The independent variables included in this study were socio-demographic factors, such as age, employment, marital status, level of education, postpartum adherence to ART, and behavioural lifestyle factors such as smoking and alcohol intake. Our variable selection was based on our review of the literature. Age was measured by asking respondents to state their age at their last birthday. Employment was measured by asking if respondents had worked for wages or salary in the past 12 months or not. 
Also, we asked participants to indicate if they were single, married, cohabiting or divorced. We also asked respondents to indicate the highest level of education they attained.

We defined postpartum adherence to ART as any episode of missed doses of ART since the birth of the index baby. Mothers who had missed taking their ART were classified as non-adherent, and those who reported no missed episode of ART were classified as adherent. Also, we asked respondents to indicate if they had ever used alcohol and if they smoke tobacco products. Responses were classified as "yes" or "no".

\section{Statistical Analysis}

We estimated mean, standard deviation and proportions for all continuous and categorical variables. Inferential statistics (crude and adjusted logistic regression models) were used to examine factors influencing EBF practices among mothers on antiretroviral therapy. All statistical analyses were carried out using the Statistical Package for Social Sciences (SPSS) for Windows version 24.0 (SPSS, Chicago, IL, USA).

\section{Results}

The participants mean age was $33 \pm 5.7$ years. Majority of the participants were 30 years and above $(69.3 \%)$, single (66.3\%), had grade 12 level of education (87.4\%), unemployed (618\%), and were on government social grant (94.5\%). Only a few participants smoked (8.1\%) or drank alcohol $(35.4 \%)$ (Table 1). 
Table 1

Socio-demographic characteristics of participants

\begin{tabular}{|c|c|c|}
\hline Variables & Frequency & Percentage \\
\hline \multicolumn{3}{|l|}{ Age } \\
\hline 24 years and less & 33 & 7.0 \\
\hline $25-29$ years & 111 & 23.7 \\
\hline $30-34$ years & 137 & 29.2 \\
\hline $35-39$ years & 121 & 25.8 \\
\hline 40 years and above & 67 & 14.3 \\
\hline \multicolumn{3}{|l|}{ Marital status } \\
\hline Single & 311 & 66.3 \\
\hline Married & 125 & 26.7 \\
\hline Cohabiting & 25 & 5.3 \\
\hline Previously married & 8 & 1.7 \\
\hline \multicolumn{3}{|l|}{ Education level } \\
\hline Grade 7 and less & 27 & 5.8 \\
\hline Grade $8-12$ & 410 & 87.4 \\
\hline Higher education & 32 & 6.8 \\
\hline \multicolumn{3}{|c|}{ Employed in a salary paying job } \\
\hline Yes & 151 & 32.2 \\
\hline No & 318 & 67.8 \\
\hline \multicolumn{3}{|l|}{ Occupation in last 12 months } \\
\hline Government employee & 15 & 3.2 \\
\hline Non-government employee & 112 & 23.9 \\
\hline Self employed & 29 & 6.2 \\
\hline Student & 23 & 4.9 \\
\hline Unemployed & 290 & 61.8 \\
\hline \multicolumn{3}{|c|}{ Receives government social grant } \\
\hline Yes & 443 & 94.5 \\
\hline No & 26 & 5.5 \\
\hline
\end{tabular}




\begin{tabular}{|lll|}
\hline Variables & Frequency & Percentage \\
\hline Smoking & & \\
Yes & 38 & 8.1 \\
No & 431 & 91.9 \\
Drank alcohol in the last year & & \\
Yes & 166 & 35.4 \\
No & 303 & 64.6 \\
\hline
\end{tabular}

\section{Prevalence Of Exclusive Breastfeeding}

The prevalence of six-month EBF was 32.0\%. The prevalence of EBF was significantly higher among married women $(36.8 \% ; p<0.001)$, unemployed women $(36.6 \% ; p<0.026)$, non-smokers $(32.7 \%)$, and those who never drank alcohol $(37.0 \% ; p<0.001)$ (Table 2). 
Table 2

Correlates of six months exclusive breastfeeding

\begin{tabular}{|c|c|c|c|}
\hline Variables & $\begin{array}{l}\text { Breastfed exclusively for } \\
\text { six months } \\
\text { n (\%) }\end{array}$ & $\begin{array}{l}\text { Did not breastfeed exclusively for } \\
\text { six months } \\
\text { n (\%) }\end{array}$ & $\begin{array}{l}\mathrm{p}- \\
\text { value }\end{array}$ \\
\hline \multicolumn{4}{|l|}{ Age } \\
\hline 24 years and less & $11(33.3)$ & $22(66.7)$ & 0.864 \\
\hline $25-29$ years & $38(34.2)$ & $73(65.8)$ & \\
\hline $30-34$ years & $41(29.9)$ & $96(70.1)$ & \\
\hline $35-39$ years & $36(29.8)$ & $85(70.2)$ & \\
\hline 40 years and above & $24(35.8)$ & $43(64.2)$ & \\
\hline \multicolumn{4}{|l|}{ Marital status } \\
\hline Single & $92(29.6)$ & $219(70.4)$ & 0.001 \\
\hline Married & $46(36.8)$ & $79(63.2)$ & \\
\hline Cohabiting & $9(36.8)$ & $16(64.0)$ & \\
\hline Previously married & $3(37.5)$ & $5(37.5)$ & \\
\hline \multicolumn{4}{|l|}{ *Education level } \\
\hline Grade 7 and less & 9 (33.3) & $18(66.7)$ & 0.170 \\
\hline Grade $8-12$ & $136(33.3)$ & $237(66.7)$ & \\
\hline Higher education & $5(16.7)$ & $25(83.3)$ & \\
\hline \multicolumn{4}{|l|}{$\begin{array}{l}\text { Employed in a salary } \\
\text { paying job }\end{array}$} \\
\hline Yes & $45(29.8)$ & $106(70.2)$ & 0.278 \\
\hline No & $105(33.0)$ & $213(67.0)$ & \\
\hline \multicolumn{4}{|l|}{$\begin{array}{l}\text { Occupation in last } 12 \\
\text { months }\end{array}$} \\
\hline Government employee & $2(13.3)$ & $13(86.7)$ & 0.026 \\
\hline $\begin{array}{l}\text { Non-government } \\
\text { employee }\end{array}$ & $33(29.5)$ & $79(70.5)$ & \\
\hline Self employed & $4(13.8)$ & $25(86.2)$ & \\
\hline Student & $5(21.7)$ & $18(78.3)$ & \\
\hline
\end{tabular}

*Some participants did not provide responses on feeding practices $(n=39)$ 


\begin{tabular}{|llll|}
\hline Variables & $\begin{array}{l}\text { Breastfed exclusively for } \\
\text { six months } \\
\mathbf{n}(\%)\end{array}$ & $\begin{array}{l}\text { Did not breastfeed exclusively for } \\
\text { six months } \\
\mathbf{n}(\%)\end{array}$ & $\begin{array}{c}\text { p- } \\
\text { value }\end{array}$ \\
\hline Unemployed & $106(36.6)$ & $184(63.4)$ & \\
\hline Smoking & & $29(76.3)$ & \\
\hline Yes & $9(23.7)$ & $290(67.3)$ & \\
\hline No & $141(32.7)$ & & \\
\hline $\begin{array}{l}\text { Drank alcohol in the } \\
\text { last year }\end{array}$ & & $128(77.1)$ & \\
\hline Yes & $38(22.9)$ & $191(63.0)$ \\
\hline No & $112(37.0)$ & \\
\hline *Some participants did not provide responses on feeding practices $(n=39)$ & \\
\hline
\end{tabular}

Factors associated with six-month exclusive breastfeeding practices (Multivariate Logistic Regression Analysis)

The results of the unadjusted logistic regression analysis indicates that being unemployed ( $\mathrm{COR}=1.77$, 95\% Cl:1.17-2.68) and having attained grade 12 or less education (COR $=2.79,95 \% \mathrm{Cl}: 1.06-7.38$ ) were significantly associated with a higher odds of practising EBF for the first six months by the participants (Table 3). However, alcohol use was associated with lower odds of practising EBF among the study participants (COR $=0.51,95 \% \mathrm{Cl}$ : $0.33-0.78)$. The clinical parameters: duration of disease, disclosure of serostatus and adherence to the current ART had no significant association with EBF practice among the mothers. Similarly, in the adjusted model, being unemployed ( $\mathrm{AOR}=1.66,95 \% \mathrm{Cl}$ : 1.08-2.56; $\mathrm{p}<0.05$ ) and having grade 12 or less level of education ( $A O R=2.76,95 \% \mathrm{Cl}: 1.02-7.49 ; \mathrm{p}<0.05)$ were significantly associated with a higher likelihood of exclusive breastfeeding, while alcohol use was significantly associated with lower odds of six-month exclusive breastfeeding (AOR $=0.54,95 \% \mathrm{Cl}: 0.34-0.85 ; \mathrm{p}<$ 0.05). The magnitude and the direction of effect persist after adjusting for important demographic, clinical and behavioural covariates (Table 3). 
Table 3

Crude and adjusted binary logistic regression analysis showing factors associated with six months of exclusive breastfeeding

\begin{tabular}{|c|c|c|}
\hline Variables & $\operatorname{COR}(95 \% \mathrm{Cl})$ & AOR $(95 \% \mathrm{Cl})$ \\
\hline \multicolumn{3}{|l|}{ Age } \\
\hline 24 years and less & $0.90(0.37-2.16)$ & $1.12(0.43-2.92)$ \\
\hline $25-29$ years & $0.93(0.49-1.76)$ & $1.02(0.51-2.01)$ \\
\hline $30-34$ years & $0.77(0.41-1.42)$ & $0.73(0.39-1.40)$ \\
\hline $35-39$ years & $0.76(0.40-1.43)$ & $0.68(0.36-1.32)$ \\
\hline 40 years and above & 1 & 1 \\
\hline \multicolumn{3}{|l|}{ Marital status } \\
\hline Single & $0.72(0.48-1.09)$ & $0.74(0.48-1.14)$ \\
\hline Married, cohabiting/divorce & 1 & 1 \\
\hline \multicolumn{3}{|l|}{ Education level } \\
\hline Grade 12 and less & $2.79(1.06-7.38)^{\star}$ & $2.76(1.02-7.49)^{\star}$ \\
\hline Higher education & 1 & 1 \\
\hline \multicolumn{3}{|l|}{ Occupation in past 12 months } \\
\hline Unemployed & $1.77(1.17-2.68)^{\star}$ & $1.66(1.08-2.56)^{\star}$ \\
\hline Employed & 1 & 1 \\
\hline \multicolumn{3}{|l|}{ Smoking } \\
\hline Yes & $0.64(0.29-1.39)$ & $0.89(0.39-2.03)$ \\
\hline No & 1 & 1 \\
\hline \multicolumn{3}{|l|}{ Drank alcohol in the past year } \\
\hline Yes & $0.51(0.33-0.78)^{*}$ & $0.54(0.34-0.85) \star$ \\
\hline No & 1 & 1 \\
\hline \multicolumn{3}{|l|}{ Adherence to ART } \\
\hline No & $0.75(0.49-1.13)$ & $0.80(0.52-1.25)$ \\
\hline Yes & 1 & \\
\hline Disclosure of status to partne & & \\
\hline
\end{tabular}

${ }^{*} \mathrm{p}<0.05$, COR: Crude Odds Ratio, AOR: Adjusted Odds Ratio, Cl: Confidence Interval 


\begin{tabular}{|c|c|c|}
\hline Variables & $\operatorname{COR}(95 \% \mathrm{Cl})$ & AOR $(95 \% \mathrm{Cl})$ \\
\hline No & $0.68(0.39-1.16)$ & $0.80(0.45-1.40)$ \\
\hline Yes & 1 & \\
\hline \multicolumn{3}{|c|}{ Duration of disease (Years) } \\
\hline 5 years and less & $1.02(0.69-1.50)$ & $1.03(0.66-1.62)$ \\
\hline Above 5 & 1 & 1 \\
\hline
\end{tabular}

\section{Discussion}

Our study aimed to examine the prevalence and the associated factors influencing six-month EBF among mothers on ART in the Eastern Cape Province, South Africa. Although many policies and programmes on six months infant breastfeeding have been promulgated in South Africa, the rate of EBF is low. In this study, the prevalence of six-month EBF was low (32.0\%), which falls far below the WHO recommendation of $90 \%$ coverage [32]. However, the EBF rate obtained in this study is comparable to the EBF rates of $31.6 \%$ among infants aged under six months [33]. Generally, the low prevalence rates of EBF in South Africa is worrying and suggests concerted interventions to promote, support and protect breastfeeding, beyond policy and programme formulations. Exclusive breastfeeding prevalence rates vary from one geographic setting to another. Some studies have reported higher EBF rates of $43.2 \%$ in Merafong subdistrict, Gauteng [34], and 35.6\% in Gert, Sibande and Mpumulanga [35] in other provinces or settings in South Africa. An earlier study by Siziba et al. [25] reported a summative low prevalence rate of $12.0 \%$ in North-West, Gauteng, Free State and Eastern Cape. Also, 18.0\%, 6.0\%, 13.0\%, 7.6\%, and 6.7\% of mothers practiced EBF up to six months in Kwa-Zulu Natal, Western Cape, Limpopo and Gauteng provinces, respectively [36-40]. Compared with other settings elsewhere, the EBF rate in our study is almost at par with rates reported in Ethiopia (30.6\%, 31.0\%) [41, 42], Bangladesh (35.0\%) [43] and India (34.0\%) [44], but higher than the EBF prevalence reported in Kaiyuan Yunnan, Southwest China (27.34\%) [45], Saudi Arabia (24.4\%) [46], USA (16.8\%) [47], Egypt (9.7\%) [48] and Nigeria (14.8\%) [49]. Yet, other studies have reported higher EBF prevalence rates in Ethiopia (88.8\%, 75.2\%; 77.3\%) [28, 50, 51], Kenya (71.4\%; 52.3\%) [52, 53], Western India (61.5\%) [54] and Tanzania (55.5\%) [55]. These differences in EBF rates reported across various countries or regions in the literature could be explained in the light of geographic variations in the interplay of cultural, economic and socio-demographic factors affecting EBF.

Notwithstanding the many advantages of breastfeeding and the strategies to promote it, EBF uptake still, remains low in many developing countries $[16,56]$. Worryingly, worldwide, only $35 \%$ of the infants are exclusively breastfed [57]. Exclusive breastfeeding is associated with child mortality in low-income countries [58,59] and morbidity [56]; thus, interventions on EBF should be accorded top priority. In this regard, there is a need to sensitise the community on the benefits and inherent problems associated with mixed feeding [47]. In the South African context, one of the pragmatic approach to promote women's 
awareness of EBF, outside of health facility channels, could be to utilise and promote the Ward-BasedOutreach-Teams (WBOT) in the community or women's groups to increase the duration of EBF. One of the cardinal objectives of WBOT is to promote and create awareness on various health issues affecting the community, as part of the government efforts of improving the primary healthcare re-engineering agenda. This is advisable because community beliefs could have considerable influence on EBF practice.

Our findings demonstrated that being unemployed and having a low level of education (secondary or less) was significantly associated with a higher likelihood of EBF, while alcohol use was significantly associated with lower odds of six-month exclusive breastfeeding practice. Previous studies have linked maternal employment with lower rates of EBF and earlier cessation of breastfeeding $[60,61]$. In this study, consistent with studies conducted in Bangladesh [43], Saudi Arabia [46], Ethiopia [62-64], Tanzania [65], Canada [66], and Guatemala [67], unemployed mothers are likely to practise EBF as compared to those who are employed. It is plausible that mothers who do not have salary employment stay or work at home, and thus, have enough opportunity while at home to breastfeed their infants. Contrastingly, employed mothers, perhaps due to the nature of their work, the challenge to return early to work after giving birth, work shifts, and maternal fatigue, may collectively hinder them from having frequent contact with their infant to provide exclusive breastfeeding. In South Africa, working mothers are granted only four months maternity leave, which may begin at any time from at least four weeks before the birth of the baby; and there are no available workplace facilities for mothers to breastfed children. This suggests that policies about maternity leave in South Africa warrant scrutiny to encourage EBF practice. This is very crucial in the context of achieving comprehensive PMTCT.

In this study, mothers with a low level of education are more incline to practise EBF. Previous studies have reported similar findings [43,68-71]. However, Mango et al. [16] study in Tanzania, found the level of education had no association with EBF practice. Other studies conducted in Ethiopia and Bangladesh reported similar findings [72,73]. The association of a lower level of education with EBF could be explained by the higher rate of unemployment in this population. As such, strategies aimed at strengthening EBF practise in this population should also address the needs of women with higher levels of education. Specifically, the concerns and fears of educated women need to be addressed during counselling sessions at ante-natal and postnatal clinics.

This study revealed that alcohol use was significantly associated with lower odds of six-month exclusive breastfeeding practice. About $22.9 \%$ of mothers drink alcohol. A study conducted in the Kilimanjaro region, Tanzania, showed that mothers' alcohol intake was associated with EBF up to 6 months [71]. Other studies have reported similar findings elsewhere [68-70, 74]. However, Mgongo et al. [56] reported a contrary result. Previous studies have linked alcohol intake with HIV and poor child immunisation $[75,76]$. A recent study has reported high binge drinking (10.8\%) among women in South Africa [77]. Alcohol consumption is widely practised in South Africa [77], at various events or celebrations such as weddings, burials, and other social events, work or community engagements. Advocacy programmes on the effects of alcohol intake during pregnancy and on lactating women is crucial. Alcohol use during pregnancy or whilst breastfeeding have negative effects on newborns, EBF, and general infant growth [80,82]. 


\section{Limitations}

Admittedly, this study has some limitations. The generalisation of the findings to the central region of the Eastern Cape is limited because the study was conducted in only two regions. Also, telephonic survey with its inherent challenges might have impacted the responses of the parturient women. Despite these limitations, our study provides useful information for future comparative studies on the factors influencing infant-feeding practices by mothers on antiretroviral therapy in the Eastern Cape Province, South Africa. Such information would be relevant in shaping maternal and child health interventions in the context of paediatric HIV reduction, at least in this setting. A qualitative study would provide better insight and understanding of the reasons why the majority of the women did not practise EBF in the region.

\section{Conclusion}

The low prevalence rates of EBF in this study is worrying and suggests concerted interventions to promote, support and protect breastfeeding, beyond policy and programme formulations. The factors affecting EBF of HIV positive mothers in this present study include employment, low levels of education and alcohol consumption. A general advocacy campaign on exclusive breastfeeding must target alcohol cessation and the creation of a favourable workplace environment for lactating mothers.

\section{Abbreviations}

AOR: Adjusted Odds Ratio, ART:Anti-Retroviral Therapy, COR:Crude Odds Ratio, Cl:Confidence Interval, EBF:Exclusive Breastfeeding, PMTCT:Prevention of Mother-to-Child Transmission, WBOT:Ward-BasedOutreach-Teams, WHO:World Health Organization

\section{Declarations}

\section{Ethics approval and consent to participate}

The Research Ethics Committee of the Walter Sisulu University approved the research protocol [(Reference: 085/2017]. Permission to implement the study protocol was granted by the Eastern Cape Department of Health and the clinical governance of the hospital. The nature and scope of the study were explained to the participants, who all gave informed consent before data collection.

\section{Consent for Publication}

Participants gave consent for sharing of the findings of the study. All authors agreed to the publication of this article. 
Data included in this study are available upon reasonable request from the corresponding author.

\section{Competing interests}

The authors declare that they have no conflicts of interest.

\section{Funding}

This work was supported by the South African AIDS Vaccine Initiative under the auspices of the South African Medical Research Council [Grant Number: SAMRC/03/2017] with funds received from the South African National Department of Health. Funders have no direct involvement in the implementation of the project or content of the manuscripts.

\section{Authors' contributions}

All authors were actively involved in the conception, design and implementation of the study protocol. DTG, OVA and AIA drafted the manuscript while AIA performed the statistical analysis. All authors have read and approved the final draft for submission.

\section{Acknowledgements}

We thank the management of Bisho, Cecilia Makiwane and Frere hospitals. We appreciate Ms. Tembisa Sizani, Mrs. Talita Plaatjie, Mrs. Nkosazana Jwacu, Ms. Rosemond Billie and the Relevance Network team for their contributions toward the successful completion of this project.

\section{References}

1. Mnyani CN, Tait CL, Armstrong J, et al. Infant feeding knowledge, perceptions and practices among women with and without HIV in Johannesburg, South Africa: a survey in healthcare facilities. Int Breastfeed J. 2016;12:17.

2. Ngoma MS, Misir A, Mutale W, et al. Efficacy of WHO recommendation for continued breastfeeding and maternal CART for prevention of perinatal and postnatal HIV transmission in Zambia. J Int AIDS Soc. 2015;18(1):19352.

3. Avert. 2019. HIV and AIDS in South Africa. Avert, 2019. https://www.avert.org/professionals/hivaround-world/sub-saharan-africa/south-africa. Accessed 22 Jan 2019.

4. Massyn N, Pillay Y, Padarath A, editors. District Health Barometer 2017/18. Durban: Health Systems Trust; January; 2019.

5. South African National Department of Health (SA NDoH). Revised Antiretroviral Treatment Guideline Update for Frontline Clinical Health Professionals. 2013. 
http://www.sahivsoc.org/Files/FDC\%20Training\%20Manual\%2014\%20March\%202013(1).pdf.

6. South African National Department of Health (SA NDoH). National Consolidated Guidelines for the prevention of mother-to-child transmission of HIV (PMTCT) and the management of HIV in children, adolescents and adults. 2015. https://sahivsoc.org/Files/ART\%20Guidelines\%2015052015.pdf.

7. United Nations Children's Fund (UNICEF) and National Department of Health. KwaZulu-Natal, South Africa (NDoH). Improving breastfeeding in the context of HIV: KZN's breakthrough on breast feeding 2010-2014. https://www.unicef.org/southafrica/SAF_resources_hivbreastfeeding.pdf.

8. World Health Organization (WHO). Guidelines on HIV and infant feeding: Principles and recommendations for infant feeding in the context of HIV and a summary of evidence. Geneva, Switzerland, 2010.

9. Binns C, Lee M, Low WY. The Long-Term Public Health Benefits of Breastfeeding. Asia Pac J Public Health. 2016;28(1):7-14.

10. West NS, Schwartz SR, Yende N, et al. Infant feeding by South African mothers living with HIV: implications for future training of health care workers and the need for consistent counseling. Int Breastfeed J. 2019;14:11.

11. Chinkonde JR, Hem MH, Sundby J. HIV and infant feeding in Malawi: public health simplicity in complex social and cultural contexts. BMC Public Health. 2012;12:700.

12. Goga AE, Doherty T, Jackson DJ, Sanders $D$, Colvin $M$, Chopra $M$, et al. Infant feeding practices at routine PMTCT sites, South Africa: results of a prospective observational study amongst HIV exposed and unexposed infants-birth to 9 months. Int Breastfeed J. 2012;7:4.

13. Waitt C, Low N, Van de Perre P, Lyons F, Loutfy M, Aebi-Popp K. Does U = U for breastfeeding mothers and infants? Breastfeeding by mothers on effective treatment for HIV infection in high-income settings. The Lancet HIV. 2018;5(9):e531-6.

14. Chaponda A, Goon TD, Hoque M. Infant feeding practices among HIV-positive mothers at Tembisa hospital, South Africa. Af J Pri Health Care Fam Med. 2017;9(1):1-6.

15. Horwood C, Haskins L, Engebretsen IM, et al. Improved rates of exclusive breastfeeding at 14 weeks of age in KwaZulu Natal, South Africa: What are the challenges now? BMC Public Health. 2018;18:757.

16. Victora CG, Bahl R, Barros AJD, et al. Breastfeeding in the 21st century: epidemiology, mechanisms, and lifelong effect. Lancet 2016;(387):475-90.

17. Yalcin SS, Berde AS, Yalcin S. Determinants of exclusive breast feeding in Sub-Saharan Africa: A multilevel Approach. Paediaatr perinat Epidemiol. 2016;30(5):439-49.

18. WHO/UNICEF. Global strategy for infant and young child feeding. http://www.who.int/nutrition/topics/infantfeeding/en/. Accessed 8 Feb, 2014.

19. Nieuwoudt S, Manderson L, Norris SA. Infant feeding practices in Soweto, South Africa: Implications for healthcare providers. SAMJ. 2018;108(9):756-62. 
20. Jama NA, Wilford A, Masango Z, et al. Enablers and barriers to success among mothers planning to exclusively breastfeed for six months: a qualitative prospective cohort study in KwaZulu-Natal, South Africa. Int Breastfeed J. 2017;12:43.

21. Statistics South Africa. South Africa Demographic and Health Survey, 2016: Key Indicator Report: SSA Pretoria, 2017.

22. Tuthill E, McGrath J, Young S. Commonalities and differences in infant feeding attitudes and practices in the context of HIV in sub-Saharan Africa: a metasynthesis. AIDS Care. 2014;26(2):21425.

23. Joint United Nations Programme on HIV/AIDS UNAIDS). Global Report: UNAIDS Report in the Global AIDs Epidemic. Geneva: UNAIDS; 2019.

24. Joint United Nations Programme on HIV/AIDS (UNAIDS). Global Report: UNAIDS Report in the Global AIDs Epidemic. Geneva: UNAIDS; 2017.

25. Siziba L, Jerling J, Hanekom S, Wentzel-Viljoen E. Low rates of exclusive breastfeeding are still evident in four South African provinces. SA J Clin Nutr. 2015;28(4):170-79.

26. Hazemba AN, Ncama BP, Sithole SL. Promotion of exclusive breastfeeding among HIV-positive mothers: an exploratory qualitative study. Int Breastfeed J. 2016;11:9.

27. Jones DL, Rodriguez VJ, Mandell LN, Lee TK, Weiss SM, Peltzer K. Influences on exclusive breastfeeding among rural HIV-infected South African women: a cluster randomised control trial. AIDS Behav. 2018;22:2966-77.

28. Gejo NG, Weldearegay HG, W/Tinsaie KT, et al. Exclusive breastfeeding and associated factors among HIV positive mothers in Northern Ethiopia. PloS ONE. 2019;14(1):e0210782.

29. Tan KL. Factors associated with exclusive breastfeeding among infants under six months of age in peninsular Malaysia. Int Breastfeed J. 2011;6(1):1.

30. Adeniyi OV, Ajayi Al, Selanto-Chairman N, et al. Demographic, clinical and behavioural determinants of HIV serostatus non-disclosure to sex partners among HIV-infected pregnant women in the Eastern Cape, South Africa. PLoS One. 2017;12(8):e0181730.

31. Adeniyi OV, Selanto-Chairman N, Owolabi EO, et al. Inequality in uptake of isoniazid prevention therapy and Mantoux test among HIV-infected pregnant women in the Eastern Cape, South Africa. BMC Public Health. 2019;19:1407.

32. WHO/UNCEF. Global strategy for infant and young child feeding. Geneva: World Health Organisation; 2003.

33. Schwartz SR, Kumwenda N, Kumwenda J, Chen S, Mofenson LM, Taylor AW. Maternal highly active antiretroviral therapy and child HIV-free survival in Malawi, 2004-2009. Matern Child Health J. 2016;20.

34. Madiba S. Factors associated with mixed feeding practices among HIV positive postnatal women in Merafong sub-district, Gauteng Province, South Africa. Afr J Phys Health Educ Recreat Dance. 2015; (Supplement 2:1):25-38. 
35. Ladzani R, Peltzer K, Mlambo MG, Phaweni K. Infant-feeding practices and associated factors of HIVpositive mothers at Gert Sibande, South Africa. Acta Paediatr. 2011;100(4):538-42.

36. Ghuman MR, Saloojee H, Morris G. Infant feeding practices in a high HIV prevalence rural district of KwaZulu-Natal, South Africa. South Afr J Clin Nutr. 2009;22(2):74-9.

37. Goosen C, McLachlan MH. Schübl. Infant feeding practice during the first 6 months of life in a lowincome area of the Western Cape Province. SA J Clin Nutri. 2014;8(2):50-4.

38. Mushaphi LF, Mbhenyane XG, Khoza LB, Amey AKA. Infant-feeding practices of mothers and the nutritional status of infants in the Vhembe District of Limpopo Province. S Afr J Clin Nutr. 2008;21(2):36-41.

39. Maclntyre UE, Baloyi P. Feeding practices of mothers of four to six week old infants. SA J Clin Nutri. 2000;13(3):127.

40. Budree S, Goddard E, Brittain K, et al. Infant feeding practices in a South African birth cohort-A longitudinal study. Matern Child Nutr. 2017;13(3):e12371.

41. Muluye D, Woldeyohannes $D$, Gizachew $M$, et al. Infant feeding practice and associated factors of HIV positive mothers attending prevention of mother to child transmission and antiretroviral therapy clinics in Gondar Town health institutions, Northwest Ethiopia. BMC Public Health. 2012;12(1):240.

42. Biks GA, Tariku A, Tessema GA. Effects of antenatal care and institutional delivery on exclusive breastfeeding practice in Northwest Ethiopia: a nested case-control study. Int Breastfeed J. 2015;10:30.

43. Hossain M, Islam A, Kamarul T, et al. Exclusive breastfeeding practice during first six months of an infant's life in Bangladesh: a country based cross-sectional study. BMC Pediatr. 2018;18:93.

44. Radhakrishnan S, Balamuruga SS. Prevalence of exclusive breastfeeding practices among rural women in Tamil Nadu. Int J Health Allied Sci. 2012;1(2):64.

45. Ruan Y, Zhang Q, Li J, et al. Factors associated with exclusive breastfeeding: A cross-sectional survey in Kaiyuan, Yunnan, Southwest China. PloS ONE. 2019;14(10):e0223251.

46. El-Gilany A-H, Shady E, Helal R. Exclusive breastfeeding in al-Hassa, Saudi Arabia. Breastfeed Med. 2011;6(4):209-13.

47. Jones JR, Kogan MD, Singh GK, Dee DL, Grummer-Strawn LM. Factors associated with exclusive breastfeeding in the United States. Pediatr. 2011;128(6):1117-25.

48. Ghwass MMA, Ahmed D. Prevalence and predictors of 6-month exclusive breastfeeding in a rural area in Egypt. Breastfeed Med. 2011;6(4):191-6.

49. Ikeako LC, Ezegwu HU, Nwafor MI, et al. Infant feeding practice among HIV positive women in Enugu, Nigeria. Br J Med Med Res. 2015;8:61-8.

50. Wakwoya EB, Zewudie TA, Gebreslasie KZ. Infant feeding practice and associated factors among HIV positive mothers in Debre Markos referral hospital East Gojam zone, North West Ethiopia. Pan Afr Med J. 2016;24:300. 
51. Sendo E, Mequanint F, Sebsibie G. Infant feeding practice and associated factors among hiv positive mothers attending ART clinic in governmental health institutions of Bahir Dar Town, Amhara Regional State, Ethiopia. J AIDS Clin Res. 2017;9(1):755.

52. Andare N, Ochol, Chege P. Determinants of infant feeding practices among mothers living with HIV attending prevention of mother to child transmission Clinic at Kiambu Level 4 hospital, Kenya: a cross-sectional study. Nutr J. 2019;18(1):64.

53. Tuthill EL, Miller D, Collins SM, et al. HIV infection, hunger, breastfeeding self-efficacy, and depressive symptoms are associated with exclusive breastfeeding to six months among women in western Kenya: a longitudinal observational study. Int Breastfeed J. 2012;15:4.

54. Sapna S, Ameya A, Rooma S, Aarti P, Rashid A, Narayan K. Prevalence of exclusive breastfeeding and its correlates in an urban slum in western India. Int eJournal Sci Med Edu. 2009;3(2):14-8.

55. Rasheed MH, Philemon R, Kinabo GD, Maxym M, Shayo AM, Mmbaga BT. Adherence to exclusive breastfeeding and associated factors in mothers of HIV-exposed infants receiving care at Kilimanjaro chiristian Medical Centre, Tanzania. East Afr Health Res J. 2018;2(1):33-42.

56. Maonga AR, Mahande MJ, Msuya SE. Factors affecting exclusive breastfeeding among women in Muheza District Tanga north eastern Tanzania: a mixed method community based study. Matern Child Health J. 2016;20:77-87.

57. Cai X, Wardlaw T, Brown DW. Global trends in exclusive breastfeeding. Int Breastfeed J. 2012;7(1):1.

58. Jones G, Steketee RW, Black RE, et al. How many child deaths can we prevent this year? Lancet. 2003;362:65-71.

59. Black RE, Victora CG, Walker SP, et al. Maternal and child undernutrition and overweight in lowincome and middle-income countries. Lancet. 2013;382(9890):427-51.

60 . Fein SB, Roe B. The effect of work status on initiation and duration of breastfeeding. Am J Public Health. 1998;88(7):1042-6.

61. Abdulwadud OA, Snow ME. Interventions in the workplace to support breastfeeding for women in employment. The Cochrane Library. 2007.

62. Setegn T, Belachew T, Gerbaba M, Deribe K, Deribew A, Biadgilign S. Factors associated with exclusive breastfeeding practices among mothers in Goba district, south east Ethiopia: a crosssectional study. Int Breastfeed J. 2012;7:1-8.

63. Liben MLGY, Adugnew M, Asrade A, Adamie B, Gebremedin E, Melak Y. Factors associated with exclusive breastfeeding practices among mothers in Dubti town, Afar regional state, Northeast Ethiopia: a community based cross-sectional study. Int Breastfeed J. 2016;11:4.

64. Chekol DA, Biks GA, Gelaw YA, et al. Exclusive breastfeeding and mothers' employment status in Gondar town, Northwest Ethiopia: a comparative cross-sectional study. Int Breastfeed J. 2017;12:27.

65. Hussein T, Mgongo M, Uriyo JG, et al. Exclusive breastfeeding rates and factors associated with exclusive breastfeeding practices in Northern Tanzania: Measurement using two different methodologies-24 hours recall and recall since birth. Int J MCH AIDS. 2019;8(1):32-43. 
66. Al-Sahab B, Lanes A, Feldman M, Tamim H. Prevalence and predictors of 6-month exclusive breastfeeding among Canadian women: a national survey. BMC Pediatr. 2010;10:20.

67. Dearden K, Altaye M, Maza Id, et al. Determinants of optimal breastfeeding in peri-urban Guatemala City, Guatemala. Rev Panam Salud Publica. 2002;12(3):185-92.

68. Lande $B$, Anderson LF, Baerug A, et al. Infant feeding practices and associated factors in the first six months of life: the Norwegian infant nutrition survey. Acta Paediatr. 2003;92(2):152-61.

69. Engebretsen IMS, Wamani H, Karamagi C, Semiyaga N, Tumwine J, Tylleskär T. Low adherence to exclusive breastfeeding in Eastern Uganda: a community-based cross-sectional study comparing dietary recall since birth with 24-hour recall. BMC Pediatr. 2007;7:10.

70. Nkala TE, Msuya SE. Prevalence and predictors of exclusive breastfeeding among women in Kigoma region, Western Tanzania: a community based cross-sectional study. Int Breastfeed J. 2011;6:17.

71. Mgongo M, Mosha MV, Uriyo JG, Msuya SE, Stray-Pedersen B. Prevalence and predictors of exclusive breastfeeding among women in Kilimanjaro region, Northern Tanzania: A population based crosssectional study. Int Breastfeed J. 2013;8(1):1-8.

72. Alemayehu T, Haidar J, Habte D. Determinants of exclusive breastfeeding practices in Ethiopia. Ethiop J Health Dev. 2009;23(1):12-8.

73. Mihrshahi S, Kabir I, Roy SK, et al. Determinants of infant and young child feeding practices in Bangladesh: secondary data analysis of demographic and health survey 2004. Food Nutr Bull. 2010;31:295-313.

74. Giglia RC, Binns CW, Alfonso HS, Scott JA, Oddy WH. The effect of alcohol intake on breastfeeding duration in Australian women. Acta Paediatr. 2008;97(5):524-29.

75. Ao TT, Sam NE, Massenga EJ, Seage GR, Kapiga SH. Human immunodeficiency virus type 1 among bar and hotel workers in northern Tanzania: the role of alcohol, sexual behaviour, and herpes simplex virus type 2. Sex Transm Dis. 2006;33(3):163-69.

76. Chen JH. Maternal alcohol use during pregnancy, birth weight and early behavioural outcomes. Alcohol. 2012;47(6):649-56.

77. Owolabi EO, Goon DT, Adeniyi VO, Seekoe E. Adult binge drinking: Prevalence, frequency and intensity among South Africans. SA Fam Pract. 2018;60(2):46-52. 